\title{
Triple-a supply chain management for automobile industry: a case study of Renault Samsung Motors
}

\author{
Wooyoung Jeong ${ }^{*}$, Minyoung Park ${ }^{* *}$ and Jung Ung Min ${ }^{* * *}$
}

\begin{abstract}
This paper presents a case study of Renault Samsung Motors (RSM) that recently encounters dynamic changes unveiling various opportunities and challenges due to increasing complexity of the supply network with growing sales volume, diversifying models, and intensifying global competition. Such competitive environment puts constant pressure on the logistics operations to reduce supply costs and lead time, but the RSM has not been paying much attention to aligning interests of supply chain partners. In 2007, RSM's effort to build partnership with new 3PLs turned abortive due to their unexpected default on the contract throwing RSM into confusion and disruptions. In this study, the problem was investigated by examining route planning process and incentive scheme of $3 P L$, and an optimization model was constructed to evaluate the performance of existing 3PL operation. The results indicate that transportation cost can be reduced by relocating consolidation centers, utilizing regional terminal and redesigning routing sequence. However, the research found that the key to successful implementation of the optimized solutions is in designing effective incentive system that induces partners to participate in continuous improvement initiatives.
\end{abstract}

Keywords: route planning, inbound logistics, incentive scheme, SCM, automobile industry

\section{Introduction}

Established in 1994, Samsung Motors was one of South Korean automobile manufacturers

\footnotetext{
Submission Date: 11/03/2009

Revision Date: $01 / 06 / 2009$

Acceptance Date: 01/06/2009

*Lecturer, Armed Forces Nursing Academy, Korea. Tel.: +82-10-3164-7736, Email: wycorea@gmail.com

* Corresponding Author, Assistant Professor, Graduate School of Logistics, Inha University, Korea. Tel.: +82-32-8608237, Email: mypark@inha.ac.kr

* Assistant Professor, Asia Pacific School of Logistics, Inha University, Korea. Tel.: +82-32-860-8235, Email: jumin@inha.ac.kr
} 
which was founded by the will of the Samsung Group's chairman, Kun-Hee Lee. However, after South Korea was hit by the Asian financial crisis, Renault acquired the Samsung Motors by buying 70\% stake for 512 million dollars in 2000 and became the first European automaker to establish operations in South Korea, under the name Renault Samsung Motors (RSM).

With the strong executive support and its operating excellence in logistics operations, RSM achieved the highest operating profit margin of $8.7 \%$ in 2006 , which was the best operating profit margin among five South Korean automobile manufacturers. In 2007, RSM became the thirdlargest carmaker after Hyundai Motors and Kia Motors in South Korea. As the export has continued to grow with the launch of the new crossover vehicle, RSM is now becoming a major Asian Export Base for Renault (www.renaultsamsungm.com).

RSM operates a manufacturing facility in Busan near the new port of Busan. Currently RSM produces SM3, SM5, SM7, and QM5 in single assembly line at the rate of 55 to $60 \mathrm{UPH}$ (Units Per Hour). As the sales volume and the number of models increase, RSM faces various challenges as well as opportunities ahead.

This paper investigates the inbound logistics operation of RSM, examining the transportation network of parts supply. As the first step, current operation of inbound supply chain was analyzed through examining past records, conducting structured interviews, and analyzing the transportation management system of the actual 3PL operation. The study also includes interviews with other leading 3PLs, discussing their route planning techniques and key challenges in designing routing models. Then, a vehicle routing model was constructed to find optimal routes that minimize total transportation cost. The model was based on an improved Greedy Algorithm using 'Combinatorics' and 'Optimize' add-in functions in Excel (Jensen, 2004). Using the optimization model, alternative solutions were presented from strategic network level, organizational level, and operational level. The results were compared with the current 3PL operation. Finally, the root cause of the existing gap between ideal and actual operation were analyzed, and possible solution alternatives were presented to overcome the existing gap in the Triple-A supply chain framework (see Figure 1). Triple-A supply chain framework consists of 'agility', 'adaptability', 'alignment', where all of three principles are core prerequisites for streamlined process control of coordinated supply chain management.

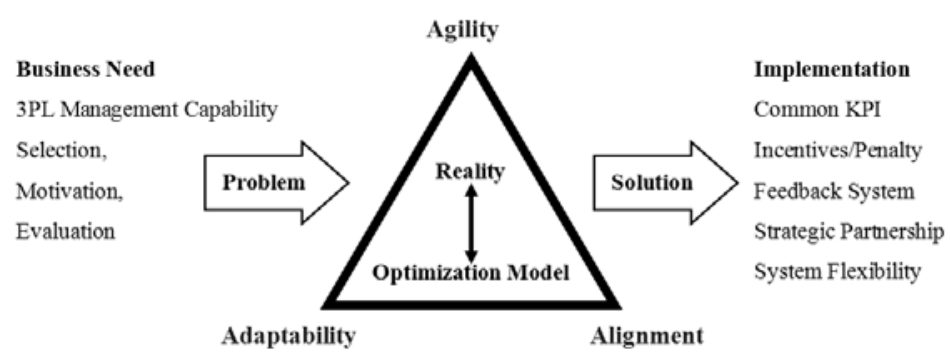

Figure 1. Research framework ${ }^{1}$

${ }^{1}$ Adopted from the Tripe-A Supply Chain (Lee, 2004) 
It should be noted that the research analyzes domestic parts supplies only, excluding global sourcing. Specifically, the optimization focuses on 27 part suppliers' cross-dock routes in Kyungin region in Korea. Because routes of direct transportation and synchronous supplies are fixed, only cross-dock routes are examined in this research. Figure 2 shows the overall map of the alternative solutions to be considered in the RSM transportation network planning process from short-term to long term, where how triple-A framework has been structured and mapped within the RSM case.

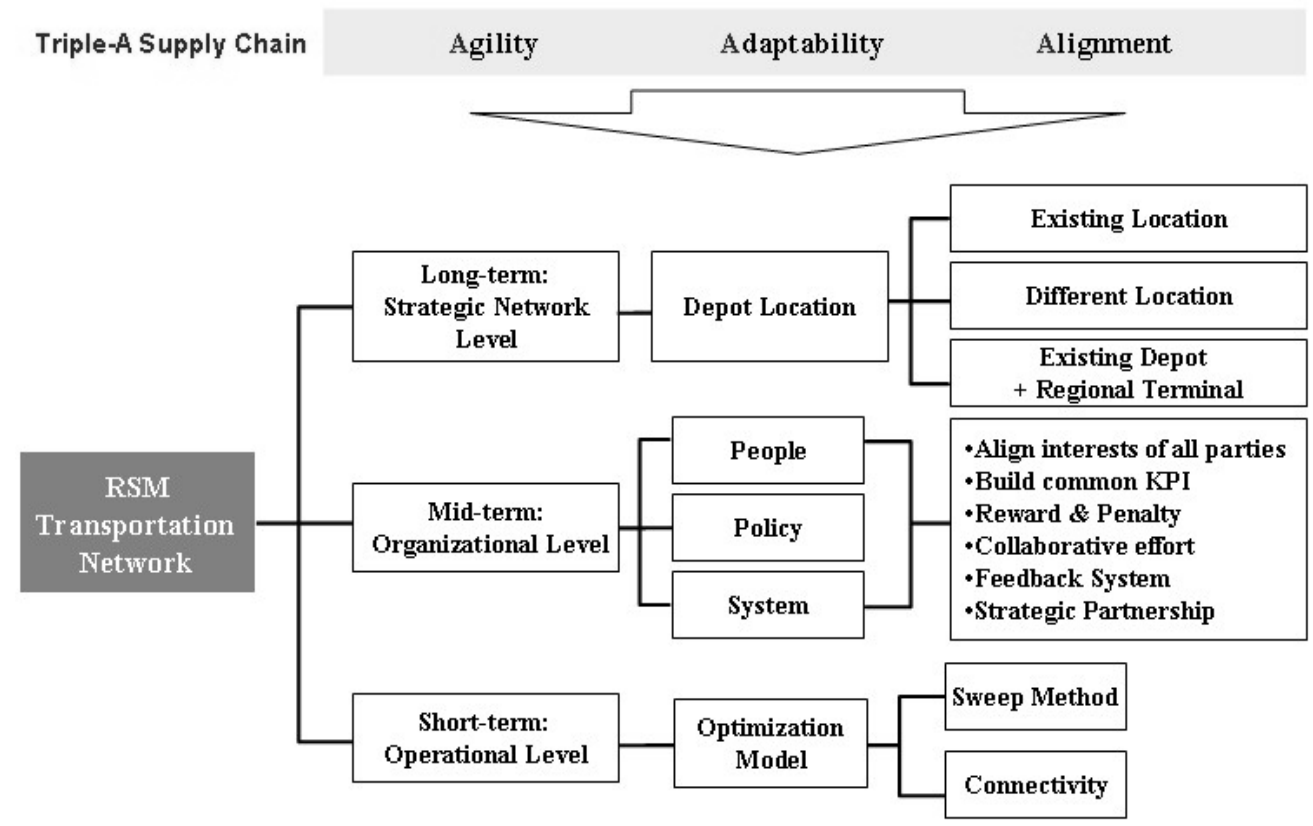

Figure 2. Transportation network planning

\section{Inbound transportation network}

\subsection{Existing 3PL operation}

As depicted in Figure 3, RSM currently operates two consolidation centers for cross-dock volume in Korea: one in Kyungin and another in Busan. Kyungin Depot consolidates parts from suppliers located in Seoul metropolitan area, South Korea. Currently RSM relies on a single 3PL, but RSM plans to increase the number of 3PLs to distribute the risk of relying on single operation. There are approximately 150 domestic parts suppliers, and the supply volumes are heavily concentrated in Busan. Transporting parts from Kyungin region are more challenging than that 
from Busan region because order quantity is small, but suppliers are located farther from the plant. 2.2 Type

3PL operates three types of transportation using 11.5 ton wing-body trucks as shown in Figure 3.

- Direct: A direct route describes an optimized scheduled flow from suppliers to RSM plant without transit via a cross-dock.

- Milk-Run: A Milk-Run is a direct route that involves pick-ups from several suppliers

- Cross-Dock: Indirect transport that involves flows of parts from supplier sites to a client plant via cross-dock at the consolidation centers.

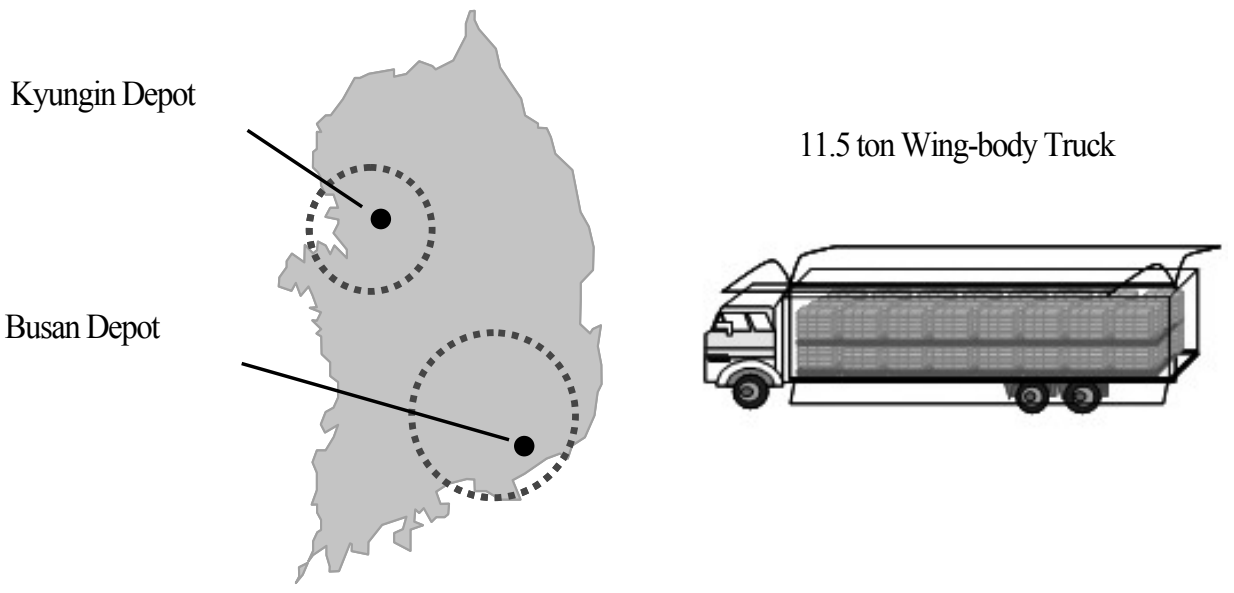

Figure 3. Depot location

\subsection{Transportation cost calculation}

In case of direct transportation, logistics cost is calculated based on the tariff which is determined by agreement between 3PL and RSM (refer to Table 1). For example, if 3PL travels $42 \mathrm{~km}$ from supplier to the RSM plant, logistics cost is 120,900 Korean Won per truck regardless of the loading rate. 
Table 1

Transportation tariff

\begin{tabular}{|c|c|c|}
\hline \multicolumn{2}{|c|}{ Distance $(\mathrm{km})$} & \multirow{2}{*}{ Tariff(won) } \\
\hline From & To & \\
\hline 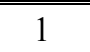 & $\overline{5}$ & 255,800 \\
\hline 6 & 10 & 66,793 \\
\hline 11 & 15 & 74,493 \\
\hline 16 & 20 & 83,700 \\
\hline 21 & 25 & 89,624 \\
\hline 26 & 30 & 97,055 \\
\hline 31 & 35 & 114,390 \\
\hline 36 & 40 & 119,510 \\
\hline 41 & 45 & 120,900 \\
\hline 46 & 50 & 122,500 \\
\hline 51 & 55 & 122,500 \\
\hline 56 & 60 & 147,405 \\
\hline
\end{tabular}

On the other hand, cross-dock cost is affected by the loading rate. For instance, if 3PL travels $10 \mathrm{~km}$ from supplier A to B carrying 5CBM (Cubic Meter), logistics costs will be calculated as follows:

Cross-dock costs

$=66,793 \times 5 \mathrm{CBM} / 36 \mathrm{CBM} \times 1.25$ (Compensation rate)

$=11,596$ Korean Won

After cross-dock volume is consolidated at the depot, the consolidated parts are transported to RSM plant by direct transportation. TABLE 2 shows the daily parts supply volume by transportation type. For example, in Busan region, about 27 TL are transported from 29 different suppliers in the region.

\section{Key issues and business need}

\subsection{Key issues}

Throughout 2007, a new transportation project has been well underway which will change logistics agreement from DDP (Delivery Duty Paid) to EXW (Ex-work). In other words, transportation costs were included in the part price, but now the transportation costs will be separated from the part price in EXW term. RSM calls it INCOTERMS project. 
Table 2

Daily parts supply volume

\begin{tabular}{c|l|l|l}
\hline & \multicolumn{1}{|c|}{ Direct } & \multicolumn{1}{|c}{ Cross-Dock } & \multicolumn{1}{c}{$\begin{array}{c}\text { Cross-Dock } \\
\text { Supplier delivers to depot }\end{array}$} \\
\hline \hline Kyungin Region & $\begin{array}{l}\text { 25 Truck Load from 12 } \\
\text { Suppliers }\end{array}$ & $\begin{array}{l}\text { 4 Truck Load from 27 } \\
\text { Suppliers }\end{array}$ & $\begin{array}{l}\text { LTL from } \\
\text { 19 Suppliers }\end{array}$ \\
Busan Region & $\begin{array}{l}\text { 27 Truck Load from 29 } \\
\text { Suppliers }\end{array}$ & $\begin{array}{l}10 \text { Truck Load from 30 } \\
\text { Suppliers }\end{array}$ & $\begin{array}{l}\text { 20 Truck Load from } \\
\text { 27 Suppliers }\end{array}$ \\
\hline
\end{tabular}

The management also realized that relying on single 3PL is a risky business even though existing 3PL service provider has been a dependable partner for the last decade. Thus, developing partnership with new 3PLs was one of the key issues to be resolved in 2007. Furthermore, the parts supply volume also increased dramatically due to launch of the new crossover vehicle in January 2008. The most immediate impacts can be summarized as follows:

- Dramatic increase in supply volume, diversity, and number of suppliers.

- Line side space shortage at plant, delays, line stoppage.

- Constant pressure to reduce inventory level within plant.

- Decreasing order lot size: Daily order placement led to more frequent delivery.

- Increasing transportation costs due to rising fuel costs and low loading rate.

- Increasing risk of relying on single 3PL operation.

- High startup costs of developing partnership with new 3PLs.

\subsection{Business need}

Due to increasing dependence on outsourcing, effective 3PL management has become increasingly important to a supply chain's competitiveness. However, RSM paid little attention to building 3PL management capabilities in terms of selection, motivation, and evaluation. Many recent studies suggest that if the primary goal of outsourcing is not short-term cost reduction, building strategic partnership results in superior performance (Christopher, 2000; Dyer et all, 1998; Harland, 1996). Thus, creating effective partnership with 3PLs require higher level of coordination between RSM and 3PLs. Through interviews with the management staffs of logistics department in RSM and analyzing the logistics operation, following business needs have been identified:

Building 3PL management capabilities can be categorized into following three elements:

- Selection: Attracting fresh 3PLs with competitive price and capability.

- Motivation: Designing incentive scheme to align interests of 3PLs for maximum performance. 
- Evaluation: Building expertise and global performance measures that help analyze resources and capability of 3PL candidates and evaluate the performance of supply chain partners including 3PLs and suppliers.

\section{Analysis of 3PL operation}

RSM has outsourced its logistics function to a single 3PL provider, Chunil Motor Freight (CMF). CMF, which is located in Busan, has been a dependable partner for RSM. Detailed route planning and daily operation is the responsibility of CMF, and RSM does not have any management control over the transportation routes. Direct transport and Cross-Dock transport is separately operated and managed, which means that mixed loading is not allowed. For route planning, no algorithm or heuristics is used by CMF due to its complexity and too many variables. Instead, the 3PL has heavily relied on the past experience and know-how, whereas a new 3PL candidate, which was supposed to operate from January 2008, has vehicle routing solution called ALLO-Agillence Lean Logistics Optimizer adopted from Toyota production system.

Currently, 3PL should register all the possible routes manually and each distance between suppliers is registered as part of the contract. For example, there are approximately 150 different cross-dock routes for only 14 suppliers. Although milk-runs can be very cost effective, milk-runs are rarely used due to RSM policy that strictly separates payment system for direct and cross-dock delivery. Because of this inflexibility, suppliers are categorized into cross-dock suppliers and direct suppliers which will be fixed by agreement among suppliers, 3PL, and RSM. Thus, even if the loading rate of direct transportation is low, only ordered amount should be delivered.

Current cross-dock routes of CMF show very similar routing sequence obtained from optimization model. The detailed explanation of the optimization model will be presented in the section V. As mentioned earlier, cross-dock routes starts and ends at the consolidation center. Under the existing incentive scheme, the transportation costs largely depend on the sequence of the supplier visit. In Kyungin region, once an 11.5 ton truck departs from the depot, it travels up to maximum of 7 suppliers for parts pick-ups. Difference between the optimal solution and the existing operation was in routes that include high cross-dock volume. Supplier with high-cross dock volume tends to be the last pick up point in the sequence even though it is not the optimal routes.

\section{Alternative solutions}

\subsection{Strategic network level}

Depot location in southern part of Kyungin region 
Currently, Kyungin Depot is located near Suwon interchange. Relocating consolidation center in the southern Kyungin region such as Ansung could be an attractive solution because it will shorten the traveling distance of direct transportation from depot to RSM plant in Busan by $20 \sim 30 \mathrm{~km}$. The cost of cross-dock was also analyzed using the optimization model. The results show that the cost of cross-dock is not significantly lower, but direct transportation costs will be reduced by 20,000 to 30,000 Korean Won per truck which can be translated into substantial savings in the long-term.

\section{Existing depot with regional terminal}

In this alternative, existing Kyungin Depot will be maintained, but another small regional terminal will be operated to cross-dock parts from the southern part of Kyungin region. It will prevent reverse transportation from the southern region to consolidation center located in Northern part of Kyungin. Cost of cross-dock was analyzed based on operating regional terminal in Daejeon, which is located about 30 40 km away from Kyungin Depot. Results showed greater cost savings than the former alternative. Consolidation in Daejun also reduces direct transportation costs to RSM plant in Busan.

\subsection{Organizational level}

\section{Redesigning incentive scheme to maximize 3PL performance}

As numerous studies and researchers suggest, aligning incentives in a supply chain results in superior performance creating competitive advantages over other supply chains(Cachon et all, 2005; Corbett et all, 2001, Narayanan et all, 2004). In the automobile industry, the relationships between 3PLs and manufacturer are developing towards strategic partnerships, rather than arm'slength relationships. In such strategic partnerships, selecting dependable partner that is capable and price competitive can be more important than anything. However what is more important is to develop and maintain trust based relationships with partners after selecting partners.

Key to building successful partnerships can be explained using experience curve as shown in Figure 4. In South Korea, 3PL industry is still in growth stage which means that new 3PLs may not have developed enough expertise and know-how in automobile industry. However, as the industry matures, experience curve will get steeper. Possible reasons for the experience curve can be attributed to the following factors: Advanced TMS system such as ALLO (Toyota TMS system), innovation in process, equipment, fuel efficient trucks, labor efficiency, experience, economies of scale, new technology, shared experience effect, value chain effect, etc.

The Figure 4 shows possible experience curve for CMF and new 3PL. Even if the initial contract price is higher than CMF, superior operating efficiency can be achieved if effective incentive scheme is provided. Effective incentive system will induce suppliers to participate in continuous improvement initiatives by offering incentives that are lower than possible cost savings. 


\section{Creating global performance measures}

Key performance indicators should be developed to measure the performance of all the partners globally. For RSM, warehouse operating costs should be included in the global performance measures if the current cross-dock structure is maintained. If the existing incentive scheme is redesigned so that $3 \mathrm{PL}$ can follow the optimal routes, loading rate will improve and the warehouse operating costs will be reduced in the end.

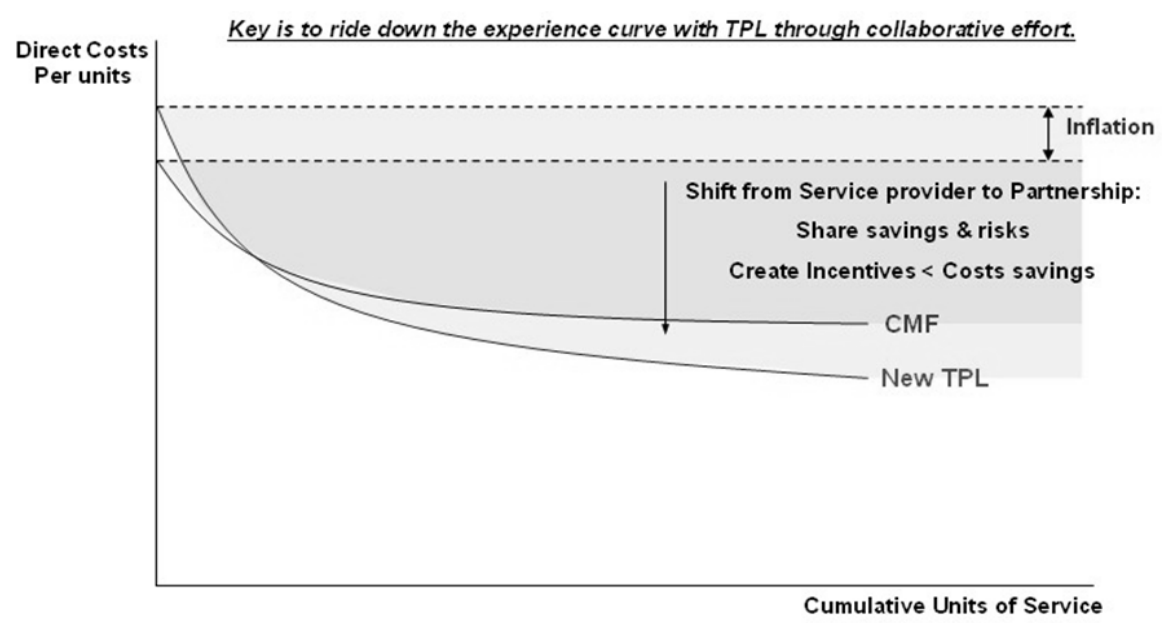

Figure 4. Experience curve and incentive system

\subsection{Operational level}

\section{Optimization model using improved greedy algorithm}

In short-term, RSM can use operations research tools to find the lowest cost cross-dock routes. Although there are a wide range of sophisticated algorithms available for this type of vehicle routing problems (Bräysy et all, 2004; Cordeau et all, 2002; Francis and Smilowitz, 2006), an improved Greedy Algorithm was selected to find an optimal route based on the following objective function:

$$
\begin{aligned}
\underset{i=1 j=1}{\operatorname{Minimize}} \sum \sum \mathrm{C}_{\mathrm{ij}} \mathrm{X}_{\mathrm{ij}} \quad \mathrm{X} 1.25 \\
\text { where } \quad \mathrm{N}=\text { number of suppliers } \\
\mathrm{C}_{\mathrm{ij}}=\text { Tariff from supply node } \mathrm{i} \text { to supply node } \mathrm{j} \\
\mathrm{X}_{\mathrm{ij}}=\text { the amount shipped from supply node } \mathrm{i} \text { to } \\
\quad \text { supply node } \mathrm{j}=\mathrm{X} / 36 \mathrm{CBM}
\end{aligned}
$$




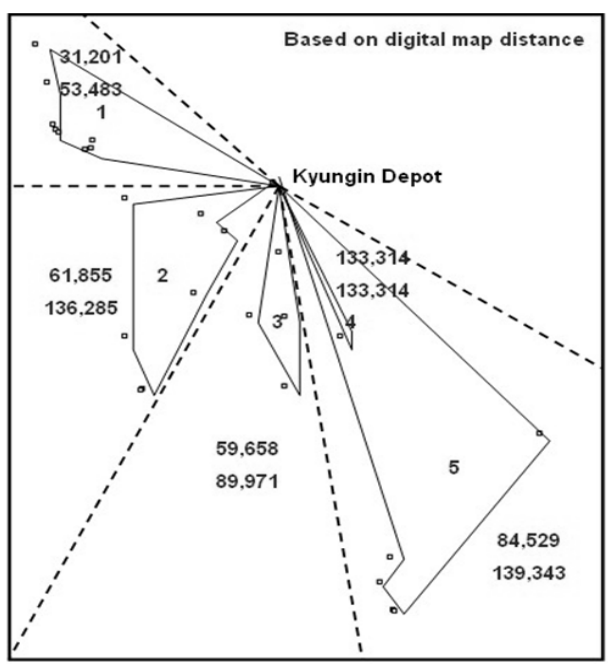

\begin{tabular}{|l|c|c|c|c|}
\hline & \multicolumn{3}{|c|}{ X-Y Coordinate } & \multicolumn{2}{l|}{ Digital Map Distance } \\
\hline & Sweep & Connectivity & Sweep & Connectivity \\
\hline Min & $\mathbf{3 2 1 , 9 8 0}$ & $\mathbf{3 0 2 , 7 1 4}$ & $\mathbf{3 7 0 , 5 5 7}$ & $\mathbf{3 3 7 , 7 1 3}$ \\
\hline Max & $\mathbf{4 4 9 , 2 6 4}$ & $\mathbf{4 4 0 , 4 4 1}$ & $\mathbf{5 5 2 , 3 9 6}$ & $\mathbf{5 0 6 , 5 5 6}$ \\
\hline Cluster & \multicolumn{5}{|c|}{ Supplier Code } & Volume \\
\hline Cluster 1 & $\begin{array}{l}\text { I401, G202, G305, G702, } \\
\text { E901, E203, E409, I801 }\end{array}$ & 0.394 \\
\hline Cluster 2 & $\begin{array}{l}\text { G301, G909, E807, } \\
\text { G911, G403, E403, }\end{array}$ & 0.753 \\
C107
\end{tabular}

Figure 5. Clustering by sweep method

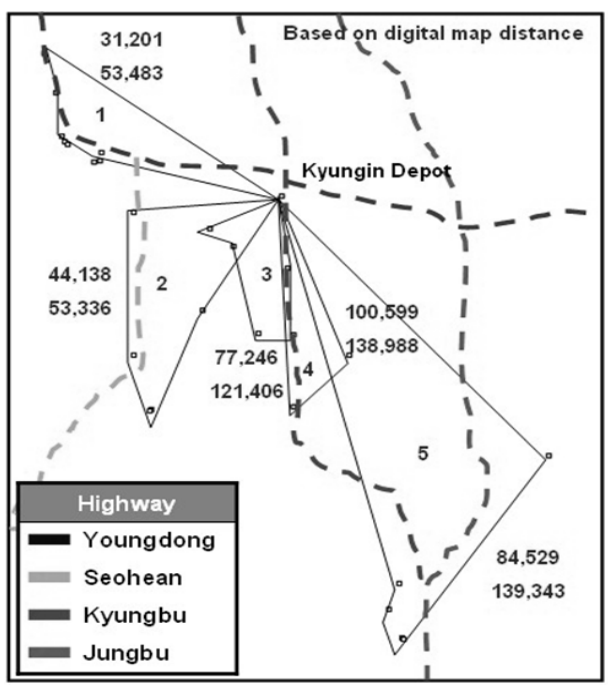

\begin{tabular}{|c|c|c|c|c|}
\hline & \multicolumn{2}{|c|}{ X-Y Coordinate } & \multicolumn{2}{c|}{ Digital Map Distance } \\
\hline & Sweep & Connectivity & Sweep & Connectivity \\
\hline Min & 321,980 & 302,714 & 370,557 & 337,713 \\
\hline Max & 449,264 & 440,441 & 552,396 & 506,556 \\
\hline
\end{tabular}

\begin{tabular}{|l|l|c|}
\hline Cluster & \multicolumn{1}{|c|}{ Supplier Code } & Volume \\
\hline Cluster 1 & $\begin{array}{l}\text { I401, G202, G305, G702, } \\
\text { E901, E203, E409, 1801 }\end{array}$ & 0.394 \\
\hline Cluster 2 & $\begin{array}{l}\text { G301, G909, E807, G911, } \\
\text { G403 }\end{array}$ & 0.421 \\
\hline Cluster 3 & $\begin{array}{l}\text { E705, E403, C107, C700, } \\
\text { E202, E410 }\end{array}$ & 0.936 \\
\hline Cluster 4 & I301, E505 & 0.936 \\
\hline Cluster 5 & $\begin{array}{l}\text { C810, E702, G910, G304, } \\
\text { E503 }\end{array}$ & 0.621 \\
\hline
\end{tabular}

Figure 6. Clustering by road connectivity

In this model, clustering-first, route-second method was used, and two clustering methods were tested for the model: one is sweep method, and another is clustering by road connectivity. The constraints were either lead time or capacity of trucks. Because cross-dock volumes tend to be low, lead time often becomes the major constraint for 3PL operation. Currently, 7 suppliers are maximum number of pick-ups in a single trip. 
As shown in Fig 5 and Fig 6, the total cross-dock costs were lower when suppliers are clustered based on road connectivity. Clustering by road connectivity is based on better highway connection between suppliers. This clustering method did not use any algorithms or models, so better clustering solution may exist. After clustering suppliers, the optimization model could be applied to find the minimum/maximum costs routes.

\section{Key findings}

This optimization model would be ideal if time schedule is negotiable with suppliers; otherwise, time windows of each supplier need to be added to the model. The main focus of this research is, however, not the optimization model itself. The optimal routes obtained from the model can provide a guideline for both 3PL and RSM, but the model itself alone cannot provide the ultimate solution. The study found that the existing incentive scheme needs to be redesigned to maximize the performance of the supply chain.

With the existing cost structure, increasing loading rate is likely to benefit RSM, but it will reduce the profit margin of 3PL. In cross-dock operation, improving loading rate will lead to lower warehouse operating costs as well as lower transportation costs. Thus, the incentive scheme should be aligned with the interests of 3PL inducing their proactive participation in improving loading rate. The key findings of the research can be summarized as follows:

- Optimal routes obtained from the model follow similar pattern with the current routes of CMF operation except high cross-dock volume, which indicates that better routing sequence can be designed by RSM.

- Either X-Y coordinate or actual distance/time obtained from online digital maps can be useful tool for analyzing various scenarios; however, the actual traveling routes of 11.5 ton wing-body truck may be different from digital map routes.

- It is possible to identify the maximum/minimum costs routes using improved Greedy Algorithm which is simple and fast (8 seconds with sample size of 10 suppliers: 2000 iterations).

- If depot is located in southern part of Kyungin region, overall transportation costs decreases (Lower cross-dock costs \& lower direct transportation costs to Busan).

- If there is no additional depot operating expense, utilizing regional terminal in Chunan, located between Suwon and Daejeon, with existing Kyungin depot results in the lowest transportation costs.

- If clustering is based on the road connectivity, the minimum/maximum cost range is lower than clustering based on sweep method.

- Cross-dock cost structure needs to be redesigned for successful implementation of the optimized solutions.

- Building 3PL management capability includes selecting dependable 3PL partners, designing effective incentive / penalty system, and creating global performance measures 
that are simple, yet strategic.

\section{Conclusions and recommendations}

In this paper, we presented a case study of Renault Samsung Motors that recently encounters dynamic changes unveiling various opportunities and challenges due to increasing complexity of the supply network with growing sales volume, diversifying models, and intensifying global competition. Such competitive environment puts constant pressure on the logistics operations to reduce supply costs and lead time. The problem was investigated from strategic level, organizational level, and operational level. By analyzing the gap between ideal and actual operations, possible solution alternatives were suggested to overcome the existing gap in the Triple-A supply chain framework.

The case study implies that RSM can improve the performance of current 3PL operation through relocating consolidation center, utilizing regional terminal, and redesigning routing sequence of cross-dock operations. In addition, new 3PLs may possess advanced TMS systems and expertise which may create steeper experience curve. However, more striking finding of this research is that RSM needs to redesign incentive scheme to improve alignment and adaptability of the supply chain. Systems, policies and technologies should constantly evolve with the changing market situation. Otherwise, supply chain performance will suffer in the long-run. Reducing the existing gap between the optimal solution and the reality requires collaborative efforts among suppliers, 3PLs, and RSM. Redesigning effective incentive scheme will be the most difficult challenges ahead; however, if it is successfully implemented, RSM will grow one step further toward achieving the Triple-A Supply Chain. The followings are some of the recommendations in order to achieve the Triple-A Supply Chain for RSM.

\section{Agility}

- Develop strategic partnership with 3PLs.

- Prepare what-if scenarios in advance.

- Review long-term, mid-term, short-term plans with 3PL.

- Assess potential long-term capability and credibility when selecting new 3PLs.

\section{Adaptability}

- Improve flexibility in system change and policy.

- Allow mixed loading of direct, milk-run, and cross dock.

- Don't try to control everything, trust partners \& rely on their services.

- Build global performance measures that evaluate the performance of all supply chain partners.

- Consider environmental issues seriously to respond to possible political and economic changes. For example, 3PLs operating more fuel efficient trucks may become the source of competitive advantage in coming years. 


\section{Alignment}

- Align objectives, interests of all supply chain partners.

- Design incentives and penalty system to improve loading rate and service level.

- Assess depot operating expense and analyze trade-off with transportation costs.

- Try to predict the possible behavior of 3PL in the light of the incentives.

- Open to suggestions from suppliers, 3PLs and employees.

- Share risk, costs, and any resulting savings with partners

\section{Acknowledgment}

This work was supported by the Korea Research Foundation Grant funded by the Korean Government (MOEHRD) (KRF-2008-005-J01601)

\section{References}

Bräysy, O., W. Dullaert, and M. Gendrea. 2004. Evolutionary algorithms for the vehicle routing problem with time windows. Journal of Heuristics. 10(6): 587-611.

Cachon, G.P. and M.A. Lariviere. 2005. Supply chain coordination with revenue-sharing contracts: strengths and limitations. Management Science. 51(1): 30-44.

Christopher, M and Juttner. 2000. Developing strategic partnerships in the supply chain: a practitioner perspective. European Journal of Purchasing and Supply Management. 6(2): 117-127.

Corbett, C. and G. DeCroix. 2001. Shared savings contracts in supply chains. Management Science. 47(7): 881-893.

Cordeau, J. F., M. Gendreau, G. Laporte, J.Y. Potvin, and F. Semet. 2002. A guide to vehicle routing heuristics. Journal of the Operational Research Society. 53: 512-522.

Dyer, J., Cho, D., and Chu, W. 1998. Strategic supplier segmentation: the next "best practice" in supply chain management. California Management Review. 40(2): 63-80.

Francis, P. and K. Smilowitz. 2006. Modeling Techniques for Periodic Vehicle Routing Problems. Department of Industrial Engineering and Management Sciences. Northwestern University. Evanston, IL.

Harland, CM. 1996. Supply chain management: relationship, chains and networks. British Journal of Management. 7: 63-80.

Jensen, A. P. 2004. Operations research models and methods. Combinatorics and optimize excel add-ins. Retrieved October 8, 2007, from Web site: http://ww.me.utexas.edu / jensen/ ORMM/index.html.

Lee, H. 2004. The triple-A supply chain. Harvard Business Review. 82 (10): 102-112. 
Narayanan, V.G. and A. Raman. 2004. Aligning incentives in supply chains. Harvard Business Review. 82 (11): 94-102.

http:/www.renaultsamsungm.com/main/index.jsp 